\title{
KOMPETENSI SUMBERDAYA MANUSIA PADA KESATUAN PENGELOLAAN HUTAN PRODUKSI DI LAMPUNG
}

\section{(COMPETENCY OF HUMAN RESOURCES IN PRODUCTION FOREST MANAGEMENT UNIT IN LAMPUNG PROVINCE)}

\author{
Riska Ersi Noviyanti, Christine Wulandari, dan Rommy Qurniati \\ Jurusan Kehutanan Fakultas Pertanian Universitas Lampung \\ Jl. Soemantri Brojonegoro No. 1 Bandar Lampung \\ Email : riskaersinoviyanti@gmail.com \\ Nomor telepon : 081273323562
}

\begin{abstract}
ABSTRAK
Kesatuan Pengelolaan Hutan Produksi (KPHP) Model Telah dibentuk wilayah-wilayah di Lampung yang meliputi KPHP Model Register 47 Way Terusan Kabupaten Lampung Tengah, KPHP Bukit Punggur Kabupaten Lampung Tengah, KPHP Model Gedong Wani Kabupaten Lampung Selatan dan KPHP Muara Dua Way Kanan (Wulandari,2011). Salah satu faktor pendukung pengelolaan (KPHP) adalah adanya sumberdaya manusia yang berkompeten. Saat ini kompetensi sumberdaya manusia di KPHP khususnya di Provinsi Lampung belum diketahui, sehingga perlu dilakukannya pemetaan sumberdaya manusia, yang akan digunakan sebagai bahan pertimbangan rekomendasi peningkatan kompetensi para pegawai KPHP di Provinsi Lampung. Tujuan penelitian ini adalah mengidentifikasi kompetensi sumberdaya manusia yang ada di setiap KPHP Provinsi Lampung dan merumuskan rekomendasi peningkatan kompetensi yang diperlukan KPHP di Provinsi Lampung. Penelitian dilaksanakan pada bulan April 2014 di KPHP Gedong Wani Kabupaten Lampung Selatan dan KPHP Way Terusan Kabupaten Lampung Tengah. Kompetensi sumberdaya manusia di KPHP Gedong Wani di bidang perencanaan hutan sebesar $49,15 \%$ dan di bidang pemanfaatan hutan sebesar 28,33\%. Kompetensi sumberdaya manusia di KPHP Way Terusan di bidang perencanaan hutan sebesar 35,07\% dan dibidang pemanfaatan hutan sebesar 36,33\%. Sumberdaya manusia di KPHP Gedong Wani dan KPHP Way Terusan di Provinsi Lampung, memiliki latar belakang pendidikan yang berbeda yaitu SMA kehutanan, S1 Kehutanan dan yang bukan dari kehutanan, serta S2 kehutanan. Kurangnya pelatihan yang diikuti menyebabkan kurang tentang perencanaan hutan dan pemanfaatan hutan baik dalam hal teknis maupun non teknis. Sehingga perlu dilakukan pelatihan untuk pegawai sesuai dengan kebutuhan dilapangan.
\end{abstract}

Kata kunci: kompetensi, sumberdaya manusia, kesatuan pengelolaan hutan produksi

\section{ABSTRACT}

Areas of Production Forest Management Unit (KPHP) Model has been established in Lampung that includes KPHP Register Model 47 Way Terusan Lampung Tengah regency, KPHP Bukit Punggur Lampung Tengah regency, KPHP Gedong Wani Lampung Selatan regency and KPHP Muara Dua Way Kanan regency (Wulandari, 2011). One of the sinifeant factor management KPHP is the competent human resources. Currently competence of 
human resources in KPHP especially in Lampung Province is not known yet, so it is necessary to do the mapping of human resources, which will be used as material for consideration on improving the competence of the employees KPHP in Lampung Province. The purpose of this research is to identify the competence of human resources that exist in every KPHP in Lampung and formulate the recommendations to increase the competence in need by KPHP in Lampung Province. The research was conducted in April 2014 in KPHP Gedong Wani Lampung Selatan regency and KPHP Way Terusan Lampung Tengah regency. Competence human resources in KPHP Gedong Wani in the field of forest planning of 49,15 $\%$ and in the field of the utilization of the forest of 28,33\%. Competence human resources in KPHP Way Terusan in areas of forest planning is 35,07\% and in the fields of the utilization of the forest of 36,33. Human resource competence in KPHP Gedong Wani and KPHP Way Terusan in Lampung Province, have different educational background like Forestry Senior High School, bachelor of Forestry of non-forestry, as well as Master of Forestry. Lack of training that followed, led to lack of forest planning and forest unilization within technical and non-technical. So they need training for employyees in accordance with the needs of nottechnical competence.

Keywords: competence, human resources, production forest management unit

\section{PENDAHULUAN}

Berdasarkan peraturan Pemerintah No. 44 Tahun 2004-2014 peraturan perencanaan Kehutanan dimaksudkan untuk memberikan pedoman dan arah yang menjamin tercapainya tujuan penyelenggara Kehutanan untuk sebesar-besarnya kemakmuran rakyat yang kerkeadilan dan berkelanjutan. Seluruh kawasan hutan Indonesia nantinya akan terbagi dalam wilayah-wilayah KPH (Kesatuan Pengelolaan Hutan) serta akan menjadi bagian dari penguatan sistem pengurusan hutan Nasional, Provinsi, Kabupaten/Kota. Berdasarkan Pasal 28 ayat (2) PP No. 44 Tahun 2004 tentang Perencanaan Kehutanan, unit pengelolaan hutan lestari terdiri dari Kesatuan Pengelolaan Hutan Konservasi (KPHK), Kesatuan Pengelolaan Hutan Lindung (KPHL), Kesatuan Pengelolaan Hutan Produksi (KPHP). Berdasarkan keputusan Menteri Kehutanan melalui SK Menhut Nomor 230/Kpts-II/2013, dibentuknya wilayah-wilayah Kesatuan Pengelolaan Hutan Produksi (KPHP) Model di Lampung yang meliputi KPHP Model Register 47 Way Terusan Kabupaten Lampung Tengah, KPHP Bukit Punggur Kabupaten Lampung Tengah, KPHP Model Gedong Wani Kabupaten Lampung Selatan, KPHP Muara Dua Kabupaten Way Kanan (Wulandari, 2011).

KPHP perlu dikelola secara lestari untuk memperoleh manfaat yang sebesar-besarnya bagi kesejahteraan masyarakat. Pembentukan (KPHP) tersebut merupakan dasar dalam pengelolaan hutan dan pemanfaatan sumberdaya hutan guna mengoptimalkan manfaat ekologi, sosial dan ekonomi. Salah satu faktor pendukung pembentukan KPHP adalah adanya sumberdaya manusia yang berkompeten. Saat ini kompetensi sumberdaya manusia di KPHP khususnya di Provinsi Lampung belum diketahui, untuk itu perlu dilakukannya pemetaan sumberdaya manusia yang akan digunakan sebagai bahan pertimbangan dalam menyusun rekomendasi peningkatan kompetensi sumberdaya manusia KPHP di Provinsi Lampung. 


\section{Tujuan penelitian}

Mengidentifikasi kompetensi sumberdaya manusia yang di KPHP Way Terusan dan KPHP Gedong Wani Provinsi Lampung dan merumuskan rekomendasi peningkatan kompetensi sumberdaya manusia yang diperlukan.

\section{METODE PENELITIAN}

\section{Waktu dan Tempat}

Penelitian dilaksanakan April 2014. Lokasi yang dijadikan tempat penelitian merupakan Kesatuan Pengelolaan Hutan Produksi (KPHP) di Provinsi Lampung, yakni; KPHP Gedong Wani Kabupaten Lampung Selatan, KPHP Way Terusan Kabupaten Lampung Tengah, masyarakat sekitar KPHP, dan Lembaga Suwadaya Masyarakat.

\section{Alat dan Objek Penelitian}

Alat yang digunakan dalam penelitian ini adalah kamera, kuesioner, laptop dan alat tulis. Objek penelitian ini adalah seluruh sumberdaya manusia di KPHP, masyarakat sekitar KPHP serta lembaga swadaya masyarakat. Pengambilan sampel penelitian ini dilakukan di 2 (dua) lokasi Kesatuan Pengelolaan Hutan Produksi Provinsi Lampung, yakni; staf KPHP Gedong Wani berjumlah 12 responden, masyarakat 8 responden, staf KPHP Way Terusan berjumlah 6 responden, masyarakat 9 responden, dan lembaga swadaya masyarakat 9 responden.

\section{Metode Penelitian}

Jenis data yang digunakan dalam penelitian ini adalah data primer dan data sekunder. Data primer dikumpulkan kompetensi sumberdaya manusia KPHP bidang perencanaan hutan (inventarisasi hutan, pemetaan hutan, statistik kehutanan, pengukuhan hutan, penatagunaan hutan) dan bidang pemanfaatan hutan (pemanfaatan hutan alam, pemanfaatan hutan tanaman, pengelolaan dan pemasaran hasil hutan, pemanfaatan usaha kawasan, pengelolaan iuran dan peredaran hasil hutan). Data sekunder yang dikumpulkan meliputi keadaan umum lokasi penelitian baik lingkungan fisik dan sosial buku literatur penunjang serta data-data lain yang berkaitan dengan penelitian yang bersumber dari pustaka ataupun instansi terkait.

Pengumpulan data dilakukan dengan wawancara dan studi pustaka. Wawancara dilakukan untuk mengumpulkan data primer, sedangkan studi pustaka digunakan untuk mengumpulkan data sekunder.

Metode yang digunakan dalam penelitian ini yaitu metode sensus karena menurut Suharsimi (2011) jika responden kurang dari 100 maka seluruh responden dijadikan sampel. Analisis data yang diperoleh disajikan dalam bentuk tabulasi dan dianalisis secara deskriptif. Jumlah pertanyaan dalam kuesioner meliputi aspek teknis sebanyak 50 pertanyaan dan aspek non teknis 50 pertanyaan ditambah beberapa pertanyaan tentang identitas responden.

\section{HASIL DAN PEMBAHASAN}

\section{Kemampuan bidang perencanaan hutan sumberdaya manusia KPHP Gedong Wani dan KPHP Way Terusan}

Secara umum kompetensi sumberdaya manusia KPHP Way Terusan lebih besar dari pada KPHP Gedong Wani, secara grafis besar disajikan pada gambar 1. 


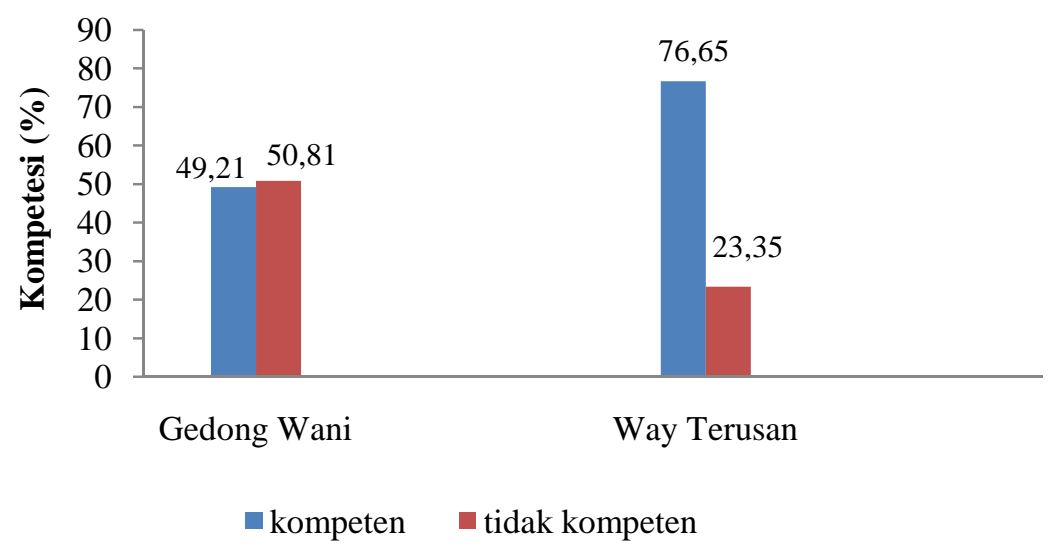

Gambar 1. Kompetensi sumberdaya manusia teknis bidang perencanaa hutan KPHP Gedong Wani dan KPHP Way Terusan.

Kompetensi sumberdaya manusia pada aspek perencanaan hutan dan kemampuan teknis, di KPHP Gedong Wani sebesar 49,21\% lebih rendah bila dibandingkan dengan sumberdaya manusia di KPHP Way Terusan sebesar 76,65\%. Hal ini dikarenakan tingkat pendidikan sumberdaya manusia KPHP Way Terusan Yang memiliki latar belakang bidang kehutanan lebih banyak (100\%), apabila dibandingkan dengan sumberdaya manusia KPHP Gedong Wani (42,85\%). Walaupun sumberdaya manusia ditingkat pendidikan S1 di KPHP Gedong Wani lebih banyak namun berlatar belakang non kehutanan. Tingkat pendidikan sumberdaya manusia di ke dua KPHP disajikan di tabel 1. Mempengaruhi tingkat pengetahuan dibidang perencanaan hutan. Menurut Dewi (2011) pengetahuan dapat dipengaruhi oleh faktor pendidikan formal. Pengetahuan sangat erat hubungannya dengan pendidikan, dimana diharapkan dengan pendidikan yang lebih tinggi maka orang tersebut akan semakin luas tingkat pengetahuannya. Hal ini dikemukakan oleh Dewi (2010), bahwa pendidikan dapat mempengaruhi seseorang, termasuk juga perilaku seseorang akan pola hidup, memotivasi serta berperan juga dalam pembangunan.

Tabel 1. Tingkat pendidikan di KPHP Gedong Wani dan KPHP Way Terusan.

\begin{tabular}{llrrrrrrrrr}
\hline No & KPHP & \multicolumn{10}{c}{ Kompetensi (\%) } \\
\hline & & SMA & $\%$ & D3 & $\%$ & S1 & $\%$ & S2 & $\%$ & Jumlah \\
\hline 1. & Gedong wani & 4 & 33,33 & - & 0 & 7 & 58,33 & 1 & 8,33 & 12 \\
2. & Way Terusan & 2 & 33,33 & - & 0 & 3 & 50,00 & 1 & 16,66 & 6 \\
\hline
\end{tabular}

Sumber: Data primer, 2014.

\section{Kemampuan bidang teknis pemanfaatan hutan sumberdaya manusia KPHP Gedong Wani dan KPHP Way Terusan}

Secara umum kompetensi sumberdaya manusia KPHP Way Terusan lebih besar dari pada KPHP Gedong Wani secara grafis disajikan pada gambar 2. 


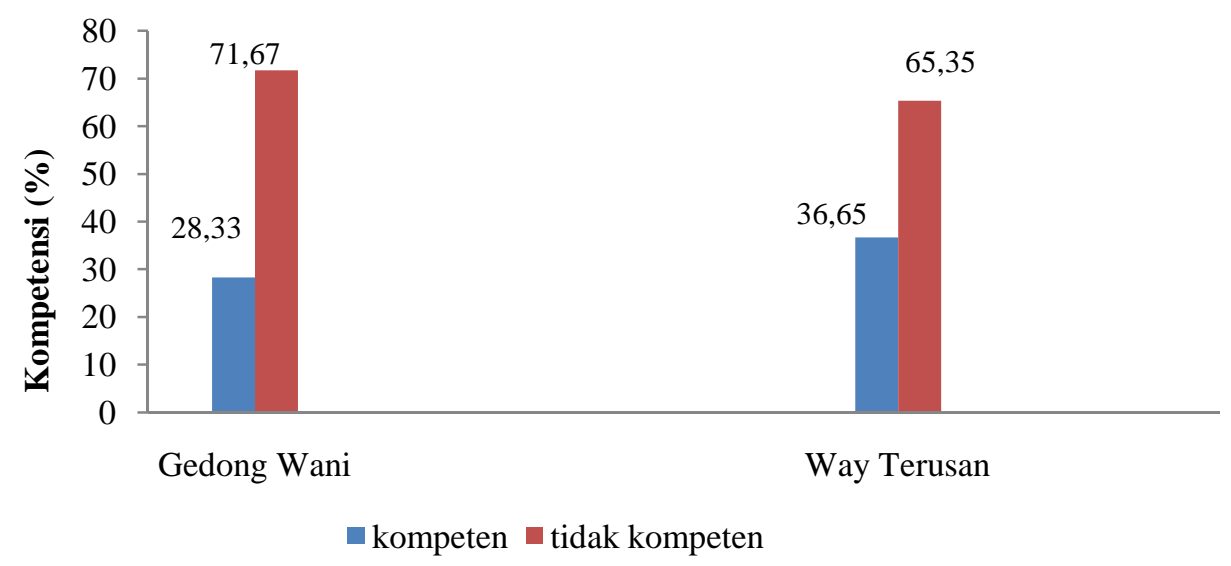

Gambar 2. Kompetensi sumberdaya manusia teknis bidang pemanfaatan hutan KPHP Gedong Wani dan KPHP Way Terusan.

Hasil penelitian menunjukkan bahwa kompetensi sumberdaya manusia kemampuan teknis dibidang pemanfaatan hutan pada KPHP Gedong Wani sebesar 28,33\% lebih rendah, sedangkan pada KPHP Way Terusan lebih tinggi sebesar 36,65\%. Hal ini menunjukkan bahwa pada kedua KPHP kemampuan teknis kurang dikuasai tentang aspek pemanfaatan hutan. Hal ini karena sumberdaya manusia dibidang kemampuan tenis kurang mengikuti pelatihan. Menurut Arso (2012) kurangnya mengikuti pelatihan sehingga responden kurang menguasai materi.

Menurut Widyarso (2012) pendidikan dan pelatihan akan mempercepat dalam meningkatkan pengetahuan dan sikap kemampuan. Oleh karena itu pendidikan dan pelatihan berperan penting dalam peningkatan kompetensi sumber daya manusia. Hal yang sama dikemukakan oleh Haedarusman (2013), berdasarkan hasil penelitian tentang analisis kinerja kemampuan di Dinas Kehutanan dan Perkebunan Kabupaten Ciamis, menunjukkan bahwa sebagian besar kinerja kemampuan kehutanan berdasarkan aspek kualitas sumber daya manusia masih perlu peningkatan. Secara rinci pelatihan yang telah diikuti sumberdaya manusia KPHP disajikan pada tabel 2.

Menurut Indrarjanti (2012) kinerja merupakan gambaran mengenai tingkat pencapaian pelaksaan suatu kegiatan atau kebijakan dalam mewujudkan sasaran, tujuan, visi dan misi oeganisasi yang ditunjukan melalui perencanaan strategi suatu organisasi dan kinerja dapat diketahui dan diukur jika individu atau sekelompok karyawan telah mempunyai kriteria atau standar keberhasilan tolak ukur yang ditetapkan oleh organisasi.

Tabel 2. Pelatihan yang diikuti KPHP Gedong Wani dan KPHP Way Terusan.

\begin{tabular}{llcc}
\hline No. & Pelatihan & \multicolumn{2}{c}{ KPHP } \\
\hline & & Gedong Wani & Way Terusan \\
\hline 1. & Pelatihan gis & $\checkmark$ & $\checkmark$ \\
2. & Pelatihan pengukuhan stock karbon & $\checkmark$ & - \\
3. & Diklat Basarhut & $\checkmark$ & $\checkmark$ \\
4. & Diklat calon KPH & $\checkmark$ & $\checkmark$ \\
5. & Diklat bisnis KPH & $\checkmark$ & $\checkmark$ \\
\hline
\end{tabular}

Sumber: Data primer, 2014. 


\section{Kemampuan non teknis bidang perencanaan hutan Sumberdaya Manusia Di KPHP Gedong Wani dan KPHP Way Terusan}

Secara umum kompetensi sumberdaya manusia KPHP Way Terusan lebih besar dari pada KPHP Gedong Wani secara grafis disajikan pada gambar 3.

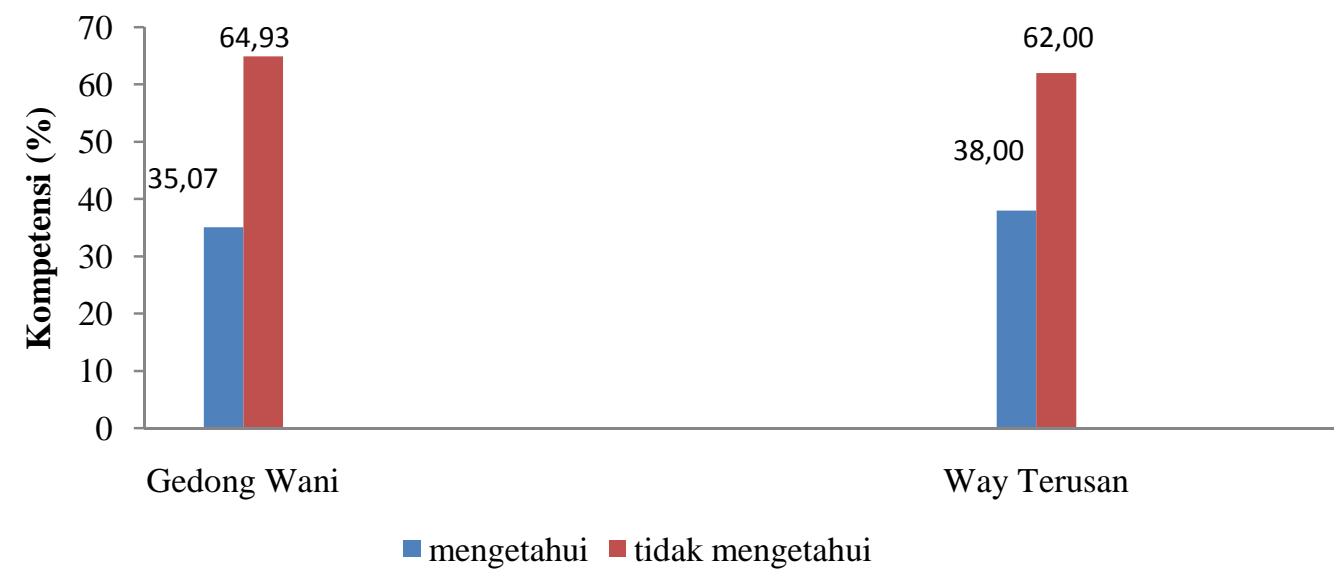

Gambar 3. Kompetensi sumberdaya manusia non teknis bidang perencanaan hutan KPHP Gedong Wani dan KPHP Way Terusan.

Hasil penelitian menunjukan bahwa kemampuan non teknis di bidang perencaan hutan menunjukkan kategori rendah, hal ini terlihat dari hasil perhitungan yang telah dilakukan. Sumberdaya manusia pada KPHP Gedong Wani untuk kemampuan non teknis yang dimiliki sebesar 35,07\% dan di KPHP Way Terusan sebesar 38,00\%, rata-rata pegawai kurang memahami tentang aspek perencanaan hutan. Aspek perencaan hutan mencakup kegiatan inventarisasi hutan, pemetaan hutan, statistik kehutanan, pengukuhan hutan, dan penatagunan hutan.

Kurangnya kemampuan non teknis di ke dua KPHP dikarenakan pegawai masih dalam proses belajar, mengingat KPHP Gedong Wani pada tahun 2010 dan KPHP Way Terusan baru terbentuk pada tahun 2009 sehingga pegawai KPHP masih dalam rangka belajar untuk menyesuaikan diri dan belajar tentang tupoksi pekerjaannya. Menurut Wiryo (2013) penilaian kinerja adalah suatu kegiatan yang dilakukan manajemen untuk menilai kinerja tenaga kerja dengan cara membandingkan kinerja dengan uraian diskripsi dalam suatu periode tertentu.

4. Kemampuan non teknis bidang pemanfaatan hutan sumberdaya manusia di KPHP Gedong Wani dan KPHP Way Terusan

Secara umum kompetensi sumberdaya manusia KPHP Way Terusan lebih besar dari pada KPHP Gedong Wani, secara garis besar disajikan pada gambar 4. 


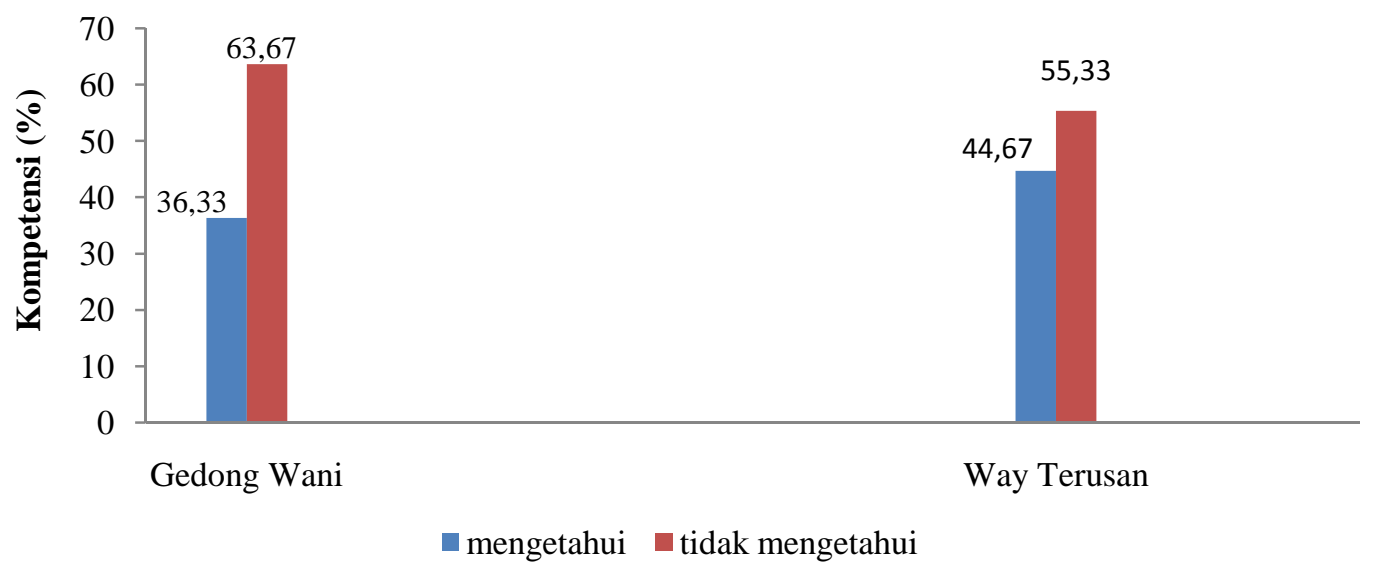

Gambar 4. Kompetensi sumberdaya manusia non teknis bidang pemanfaatan hutan KPHP Gedong Wani dan KPHP Way Terusan.

Hasil penelitian tentang kompetensi non teknis di aspek pemanfaatan hutan sumberdaya manusua di KPHP Gedong Wani sebesar 36,33\% dan sumberdaya manusia di KPHP Way Terusan sebesar 44,67\%. Secara grafis dijajikan pada gambar 4 KPHP Gedong Wani memiliki kompetensi yang lebih rendah dibandingkan KPHP Way Terusan. Hal ini disebabkan karena tingkat pengalaman dan pemahaman sumberdaya nanusia KPHP Way Terusan yang lebih baik terlihat dari persentase sumberdaya manusia dengan pendidikan S1 dan S2 dari bidang kehutanan lebih dibandingkan dengan sumberdaya manusia di KPHP Gedong Wani yang memiliki pendidikan S1 didominasi bidang non bidang Kehutanan.

Tabel 6. Persepsi masyarakat terhadap di bentuknya KPHP Gedong Wani dan KPHP Way Terusan.

\begin{tabular}{|c|c|c|c|c|c|c|}
\hline \multirow{2}{*}{ No. } & \multirow{2}{*}{ КРНP } & \multicolumn{5}{|c|}{ Kompetensi } \\
\hline & & Sangat setuju & Setuju & Kurang setuju & Tidak setuju & Jumlah \\
\hline 1. & Gedong Wani & 75 & 12,5 & & 12,5 & 100 \\
\hline 2. & Way Terusan & 100 & - & & - & 100 \\
\hline
\end{tabular}

Sumber: Data primer, 2014.

Besarnya nilai yang diperoleh dari hasil wawancara dengan responden di KPHP Way Terusan menggunakan kuisioner, 100\% masyarakat sangat setuju dengan dibentuknya KPHP Way Terusan. Pada pembentukan KPHP Gedong Wani ada 12,5\% yang tidak setuju dengan dilakukanya kegiatan-kegiatan yang ada di KPHP Gedong Wani karena sebagian masyarakat ada yang tidak dilibatkan dalam kegiatan tersebut. Disajikan pada (Tabel 3).

\section{Persepsi LSM terhadap dibentuknya KPHP}

Hasil wawancara dengan lembaga swadaya masyarakat menyatakan $100 \%$ setuju terhadap dibentuknya KPHP. Hal ini menunjukan bahwa responden mendukung dilakukan kegiatan inventarisasi hutan, pemetaan hutan, statistik kehutanan, pengukuhan hutan di 
KPHP Gedong Wani dan KPHP Way Terusan. Secara umum setujunya LSM terhadap dibentuknya KPHP agar pengelolaan hasil kayu maupun non kayu terkelola dengan baik (Azhari, 2008).

\section{Rekomendasi peningkatan kompetensi yang diperlukan KPHP Gedong Wani KPHP dan KPHP Way Terusan di Provinsi Lampung}

Kinerja sumberdaya manusia KPHP Gedong Wani dan KPHP Way Terusan baik dibidang teknis mampu non teknis kurang kompeten hal ini dikarenakan pegawai di ke dua KPHP jarang mengikuti pelatihan. Berdasarkan tingkat pendidikan sumberdaya manusia KPHP Gedong Wani (Tabel 1) 42,85\% bidang kehutanan sehingga mempengaruhi kompetensi sumberdaya manusia dan perlu dilakukan pendidikan ke jenjang yang lebih tinggi pada bidang kehutanan. Pendidikan KPHP Way Terusan pada (Tabel 1) 100\% semua dari bidang kehutanan namun ada yang perlu melanjutkan ke S1 dibidang kehutanan. Pelatihan yang sudah diikuti pada (Tabel 2) KPHP Gedong Wani dan KPHP Way Terusan itu semua masih kurang untuk pelatihan yang pernah diikuti, harus lebih banyak lagi pelatihan yang diikuti dalam bidang kehutanan, sehingga dapat mempengaruhi kompetensi sumberdaya manusia yang diperlukan. Pelatihan yang baik adalah pelatihan yang sesuai dengan kebutuhan pegawai. Tidak ada manfaat jika pelatihan yang dilaksanakan tidak atau kurang sesuai dengan kebutuhan pegawai. Sehingga untuk meningkatkan pengetahuan dan keterampilan dibidang Kehutanan perlu diadakan pelatihan yang sesuai dengan kebutuhan dan penerimaan pegawai pada masa yang akan datang, perlu disesuaikan dengan kebutuhan lapangan (Nurhidayat, 2009).

\section{KESIMPULAN DAN SARAN}

\section{A. Kesimpulan}

1. Kompetensi sumberdaya manusia di KPHP Gedong Wani di bidang perencanaan hutan termasuk katagori kurang mampu sebesar $49,15 \%$ dan di bidang pemanfaatan hutan termasuk katagori kurang mamampu sebesar $28,33 \%$. Kompetensi sumberdaya manusia di KPHP Way Terusan di bidang perencanaan hutan termasuk katagori mampu sebesar $76,65 \%$ dan di bidang pemanfaatan hutan termasuk katagori kurang mampu sebesar $36,65 \%$.

2. Pegawai KPHP Gedong Wani dan KPHP Way Terusan di Provinsi Lampung, memiliki pendidikan yang berbeda yaitu SMA Kehutanan, S1 Kehutana serta S2 dan yang bukan dari kehutanan, kurangnya pelatihan yang diikuti untuk pegawai menyebabkan pegawai kurang memahami tentang perencanaan hutan dan pemanfaatan hutan.

\section{B. Saran}

Perlunya dilakukan pelatihan untuk pegawai KPHP Gedong Wani dan KPHP Way Terusan guna meningkatkan sumberdaya manusiayang ada.

\section{DAFTAR PUSTAKA}

Arso. 2012. Kinerja pegawai. Buku. Universitas Sumatra Utara. Medan. 14 p.

Azhari. 2008. Partisipasi Masyarakat Petani dalam Pencegahan Penyakit Filariasis di Kabupaten Asahan. Skripsi. Universitas Sumatra Utara. Medan. 16 p. 
Dewi A, P.K. 2011. Pengaruh Tingkat Pendidikan, Pengaruh, Sikap Dan Terpaan Iklan Layanan Masyarakat. Jakarta. Universitas Bandung. Jurnal tingkat pendidikan. 10:11-2011.

Dewi B,W.A. 2010. Teori dan Pengukuhan Pengetahuan Sikap Dan Perikemanusiaan Dilengkapi Contoh Kuisioner. Yogyakarta: Nuha Media. Jurnal pengetahuan sikap. $11: 12-2010$.

Haedrusman, D. 2013. Analisis Kinerja Pegawai Dinas Kehutanan Dan Perkebunan Kabupaten Ciamis Di Lihat Dari Aspek Kualitas Sumberdaya Manusia. Universitas Galuh. Jurnal kinerja pegawai. 13:14-2013.

Indrarjati, P. 2012. Pengaruh Kemampuan Usaha Dan Dukungan Organisasi Terhadap Kinerja. Wiyga Manggala. Jurnal sekolah tinggi ilmu ekonomi. 02:05-2012.

Matroyo. 1987. Kompetensi Sumberdaya Manusia. Skripsi. Universitas Yogyakarta. 124 p.

Nefina. 2005. Pengertian Kompetensi Non Teknis. Skripsi. Mandar Maju. Bandung. 16 p.

Nurhidayat. 2009. Kompetensi Pegawai. Skripsi. Universitas Erlangga. Surabaya. 156 p.

Setyowati, E. 2010. Pengembangan Sumberdaya Manusia Berbasis Kompetensi. Universitas Semarang. Jurnal solusi untuk meningkatkan kinerja organisasi 9:10 -2011.

Suharsimi, A. 2011. Dasar-Dasar Evaluasi Pendidikan. Buku . Bumi Aksara. Jakarta. 26 p.

Walshetal. 2001. Teori Tentang Kompetensi Teknis dan Faktor-faktor Mempengaruhi Kompetensi Teknis. Skripsi. Jakarta. 145 p.

Widyorso, D.W. A. 2012. Analisis Kinerja Pegawai di Kelurahan Karang Kidul Kecamatan Semarang Tengah Kota Semarang. Jurusan Administrasi Publik Fakultas Ilmu Sosial Dan Ilmu Politik Universitas Diponegoro Semarang. Jurnal kinerja pegawai.

10:11-2012.

Wiryo. 2013. Kinerja Pegawai. Skripsi. Universitas Jakarta. Jakarta. 196 p.

Wulandari, C. 2011. Kebijakan Dan Peraturan Perundangan Kehutanan. Buku.Universitas Lampung. Bandar Lampung. 17 p. 
Vol. 4 No. I, Januari 2016 (II-20)

Halaman ini sengaja dikosongkan 